\title{
Efficacy of Intraoperative Neuromonitoring during Thyroidectomy with Transcutaneous Adhesive Skin Electrodes
}

\author{
Sang Gyu Seo ${ }^{1 *}$, Hyoung Shin Lee ${ }^{2 *}$ Ki Hun $\mathrm{Jo}^{2}$, Sung Won $\mathrm{Kim}^{2}$, and Kang Dae Lee ${ }^{2}$ \\ ${ }^{1}$ Departments of Medicine, ${ }^{2}$ Otolaryngology-Head and Neck Surgery, Kosin University College of Medicine, Busan, Korea
}

\section{피부 부착형 전극을 이용한 갑상선 수술 중 신경 모니터링의 효용성}

서상규 ${ }^{1 *} \cdot$ 이형신 ${ }^{2 *} \cdot$ 조기헌 ${ }^{2} \cdot$ 김성원 $^{2} \cdot$ 이강대 ${ }^{2}$

고신대학교 의과대학 의학과, ${ }^{1}$ 이비인후과학교실 ${ }^{2}$

\author{
Received September 5, 2020 \\ Revised October 26, 2020 \\ Accepted October 28, 2020 \\ Address for correspondence \\ Kang Dae Lee, MD, PhD \\ Department of Otolaryngology- \\ Head and Neck Surgery, \\ Kosin University \\ College of Medicine, \\ Kosin University Gospel Hospital, \\ 262 Gamcheon-ro, Seo-gu, \\ Busan 49267, Korea \\ Tel $+82-51-990-6470$ \\ Fax $+82-51-245-8539$ \\ E-mail kdlee59@gmail.com \\ *These authors contributed equaly to \\ this work.
}

Background and Objectives Variable types of electrodes for intraoperative neuromonitoring (IONM) during thyroid surgery have been introduced to make up for the shortcomings of conventional endotracheal electromyogram tube. In this study, we sought to evaluate the efficacy of transcutaneous adhesive skin electrodes for IONM of recurrent laryngeal nerve (RLN) during thyroidectomy.

Subjects and Method A total 97 nerves at risk of 80 patients were enrolled in this study. Two disposable adhesive skin electrodes were attached at both upper margins of thyroid cartilage. Using NIM 3.0 system (Medtronic), we recorded the amplitude and latency of signals of vagus nerve and RLN following the standard procedure of IONM. Clinicopathologic factors as well as the preoperative and postoperative vocal cord functions of the patients were analyzed. Results IONM was successful in all nerves at risk without any false loss of signals. There were no complications nor any significant time delay due to adhesive skin electrodes. The mean amplitudes from the vagus nerve (V1) and RLN (R1) were $230.64 \mu \mathrm{V}$ and $293.48 \mu \mathrm{V}$, respectively. Two nerves at risk showed loss of signal and the two patients showed postoperative temporary vocal cord paralysis. The amplitude of signals from the vagus nerve (V1, V2) was significantly higher in the lower body mass index (BMI) group compared to that of the higher BMI group.

Conclusion IONM using transcutaneous skin electrodes may be considered as an alternative technique for IONM during thyroid surgery.

Korean J Otorhinolaryngol-Head Neck Surg 2021;64(6):416-21

Key Words Electrodes · Nerve monitoring $\cdot$ Neuromonitoring ·

Recurrent laryngeal nerve $\cdot$ Thyroidectomy.

\section{서 론}

2016년 국가 암 발생 통계자료에 따르면 여성에서 갑상선 암은 조발생률 10만 명당 80.2명으로 유방암 다음으로 발생

This is an Open Access article distributed under the terms of the Creative Commons Attribution Non-Commercial License (https://creativecommons.org/licenses/by-nc/4.0) which permits unrestricted non-commercial use, distribution, and reproduction in any medium, provided the original work is properly cited.
률이 높은 암이다. ${ }^{1)}$ 갑상선암의 대부분을 차지하는 유두상 암은 일반적으로 예후가 좋지만, 갑상선 수술 후 되돌이후두 신경손상, 상후두신경손상, 부갑상선 기능저하증, 출혈, 감염, 장액종 등의 합병증이 발생할 수 있다. ${ }^{2}$ 그중 되돌이후두신 경의 손상으로 인한 성대 마비와 이로 인한 음성장애, 연하 장애, 호흡곤란 등은 환자의 삶의 질을 저하시킬 뿐만 아니 라 직업을 잃게 할 수도 있다. 
최근의 메타분석에 따르면 갑상선 수술 중 신경 모니터링 (intraoperative neuromonitoring, IONM)은 되돌이후두신 경의 손상을 유의하게 감소시키고 ${ }^{3)}$ 외과의의 육안으로 되돌 이후두신경을 발견하기 전에 신경의 위치를 예측하는 데 도 움을 주며(mapping), 또한 신경을 노출시킨 후 견인에 의한 신경손상을 예방할 수 있도록 모니터링(monitoring)을 가능 하게 한다. ${ }^{4}$ 또한 술후 신경의 기능을 예측할 수 있게 함으로 써 양측성 성대 마비 등의 심각한 합병증을 예방하는 데도 도움이 될 수 있다. ${ }^{5)}$

표준적인 IONM 방법은 기관삽관용 전극을 이용한 근전도 (electromyogram, EMG) 튜브를 사용하는 것으로 전세계적 으로 가장 널리 활용되고 있다. 그러나, 수술 중 $\mathrm{EMG}$ 튜브에 부착되어 있는 표면 전극(surface electrode)이 튜브의 상하의 움직임 혹은 회전으로 인해 위양성(false positive) 신호 즉, 위 신호소실(false loss of signal)이 발생할 수 있는 단점이 있 다. ${ }^{6} \mathrm{Wu}$ 등근 이러한 $\mathrm{EMG}$ 튜브의 단점을 보완하기 위해 피부 부착형 전극을 사용하여 IONM을 시행하였다. 동물실 험 결과 피부 부착형 전극은 기존 $\mathrm{EMG}$ 튜브 전극과 동일한 신경 손상 정보를 제공할 뿐만 아니라, $\mathrm{EMG}$ 튜브의 위치 변 화에 의한 위신호소실 또한 피할 수 있었다. 본 저자들은 앞 서 피부 부착형 전극을 이용한 갑상선 수술 중 신경 모니터 링이 EMG 튜브에 의한 IONM에 비해 전극 신호의 진폭(amplitude)이 낮다는 한계점이 있음에도 불구하고, $\mathrm{EMG}$ 튜브 에서 얻은 신호와 동일한 모양의 이상성(biphasic) 신호가 관 찰되어 IONM을 시행하는 데 문제가 없음을 확인하였다. ${ }^{8)}$ 뿐만 아니라 $\mathrm{EMG}$ 튜브의 표면 전극이 성대로부터 떨어짐에 따라 신호가 사라지는 경우에도 피부 전극을 통한 IONM에 서는 신호가 안정적으로 관찰되었다. 향후 피부 부착 전극을 이용한 IONM이 활용되기 위해서는 EMG 튜브 삽입 없이 피 부 부착 전극만으로도 갑상선 수술 중 IONM이 가능하다는 것을 확인할 필요가 있어 본 연구를 진행하게 되었다.

\section{대상 및 방법}

\section{대 상}

2019년 7월 2019년 12월까지 고신대학교 복음병원 이비인 후과에서 피부 전극을 이용한 수술 중 신경 모니터링하에 갑 상선 절제술을 받은 환자 80명(97 nerves at risk)을 대상으로 후향적 차트 분석을 시행하였다. 본 연구는 본 기관의 연구윤 리위원회의 승인을 받고 시행되었다(IRB No. 2019-12-022). 선행 연구 ${ }^{8}$ 에서 소개한 방법과 동일하게 갑상 연골 상연 높 이 양측 피부에 피부 부착형 전극을 부착하여, IONM을 시 행한 환자들의 기록지를 분석하여 결측치가 없는 경우만 연
구에 포함시켰다. ${ }^{9}$ 이전에 경부 수술 혹은 방사선 치료를 받 은 환자, 종양이 되돌이후두신경을 침범한 환자, 임상적으로 중심부나 측부 경부 림프절 침범이 있는 환자, 술전 성대 마 비가 있는 환자, IONM의 금기 사유가 있는 환자는 모두 제외 시켰다. 수술 받은 환자들의 나이, 성별, 종양의 크기, 종양의 $\mathrm{T}$ classification, 체질량지수(body mass index, BMI), 술후 성대 마비 유무 등을 분석하였으며, 종양의 크기는 수술 후 병리 검사상 최대 길이로 정하였다. 환자군을 $\mathrm{BMI}$ 의 평균값 을 기준으로 두 군으로 나누어 IONM 결과를 비교하였다.

\section{신경 모니터링}

모든 환자는 $1.5 \times 2.0 \times 2.5 \mathrm{~cm}$ 크기의 일회용 부착용 전극 (DSE3125, Medtronic Xomed Inc., Jacksonville, FL, USA) 두 개를 갑상 연골의 상연 양측에 부착하였다. 전극을 부착 하고 고정하는 데 소요된 시간은 1 분 이하였다. 모든 환자는 편측 혹은 양측의 신경 모니터링을 위하여 NIM-Neuro 3.0 system(Medtronic, Jacksonville, FL, USA)의 근전도 감시 장치를 사용하였다. 수술 중 신경 모니터링은 표준적 방법을 이용하여 V1-R1-R2-V2 순서로 측정하였고, 각 신호의 진폭 $(\mu \mathrm{V})$ 과 잠복기 $(\mathrm{msec})$ 를 기록하였다. ${ }^{10)} \mathrm{Wu}$ 등 ${ }^{11)}$ 의 연구에서와 같이 되돌이후두신경의 근위부에서 $\mathrm{R} 2 \mathrm{p}$, 원위부에서 $\mathrm{R} 2 \mathrm{~d}$ 를 각각 측정하여 술후 손상이 있는지를 확인하였다.

\section{통계 분석}

통계 분석을 위해 SPSS v 2.0(SPSS Inc., Chicago, IL, USA)을 이용하였다. 모든 수치 데이터는 평균표준편차로 기록하였다. 연속 변수에 대한 비교는 Student's t-test를 이 용하였고, 연속변수 간의 상관관계 분석은 Pearson 상관분 석으로 시행했다. 통계적인 유의성은 $p$ value가 0.05 미만인 경우에 있다고 하였다.

\section{결 과}

환자의 임상병리학적 특징은 Table 1에 요약되어 있다. 모든 nerves at risk에서 피부 전극을 이용한 부착형 IONM으로 인한 부작용은 관찰되지 않았으며, 이로 인해 수술 지연과 같은 수술 과정에서의 문제도 발생하지 않았다. 모든 환자의 $\mathrm{IONM}$ 에서 이상성(biphasic)의 신호가 관찰되었다(Fig. 1). 두 개의 nerves at risk에서 수술 중 신호 소실이 발생하였으며 두 환자 모두에서 술후 성대 마비가 관찰되었다. 한 개의 신경 에서는 신경 감시의 시작부터 신호가 나타나지 않은 type 2 global injury가 관찰되었고, ${ }^{12)}$ 나머지 한 개의 신경에서는 $\mathrm{R} 2 \mathrm{~d}$ 의 신호는 유지되었으나, R2p, V2의 신호가 관찰되지 않 
Table 1. Clinicopathologic factors of patients enrolled in the study

\begin{tabular}{lc}
\hline \multicolumn{2}{c}{ Clinicopathologic factors } \\
\hline Age $($ mean \pm SD $)$ & $47.97 \pm 12.85(21-78)$ \\
Sex & 80 \\
Female & 17 \\
Male & $24.39 \pm 3.44(18.11-36.63)$ \\
Body mass index $\left(\mathrm{kg} / \mathrm{cm}^{2}\right)$ & $0.99 \pm 0.91(0.2-4.8)$ \\
Size of tumor $(\mathrm{cm})$ & \\
Pathology & 87 \\
Papillary thyroid carcinoma & 61 \\
T1a & 14 \\
T1b & 2 \\
T2 & 1 \\
T3a & 8 \\
T3b & 10 \\
Follicular adenoma & \\
\hline
\end{tabular}

SD: standard deviation

는 type 1 segmental injury로 확인되었다. 이후 외래를 통한 추적 관찰에서 전자 환자의 성대 마비는 2 개월째 호전되는 양상을 보였고, 다른 환자는 1 개월째 회복되었다. 그 외 모든 환자의 IONM 과정에서 미주신경 $\mathrm{EMG}$ 에서 $100 \mu \mathrm{V}$ 이상의 이상성 신호가 확인되었고 위신호소실이 발생한 경우는 확인 되지 않았다. 두 건의 성대 마비를 제외한 95개 신경의 IONM 과정에서 V1-R1-R2p-R2d-V2 단계별 진폭은 Table 2에 정 리하였다. 신경의 $\mathrm{V} 1, \mathrm{~V} 2$ 의 진폭 비(V2/V1 비)와 R1, R2p의 진폭 비(R2p/R1 비)는 각각 $1.12 \pm 0.24(0.60 ~ 2.26)$ 와 $1.13 \pm$ $0.25(0.80 \sim 2.08)$ 였으며 V2와 R2p가 V1과 R1의 진폭에 비해 각각 $50 \%$ 이상 감소된 경우는 없었다. Table 3에는 IONM 각 과정에서의 잠복기를 정리하였다. Table 4에는 환자군의 평균 $\mathrm{BMI}\left(26.26 \mathrm{~kg} / \mathrm{m}^{2}\right)$ 를 기준으로, BMI가 평균 이상인 군 $(\mathrm{n}=45)$ 과 $\mathrm{BMI}$ 가 평균 미만인 군 $(\mathrm{n}=50)$ 으로 나누어 각 $\mathrm{IONM}$ 과정에서의 진폭을 정리하였다. $\mathrm{BMI}$ 가 높은 군보다 낮은 군 에서 $\mathrm{V} 1(p=0.020)$ 과 $\mathrm{V} 2(p=0.030)$ 의 amplitude가 유의하게 높 았고, R1-R2p-R2d에서는 유의한 차이가 없었으나, BMI가 낮은 군에서 진폭이 높은 경향을 보였다. Pearson 상관 분석 에서도 $\mathrm{V} 1$ (상관계수 $-0.228, p=0.025$ ), $\mathrm{V} 2$ (상관계수 -0.219 , $p=0.032)$ 로 나타나 $\mathrm{BMI}$ 와 진폭이 역의 상관관계를 보임을 확인할 수 있었다. $\mathrm{BMI}$ 에 따른 잠복기의 차이는 없었다.

\section{고 찰}

본 연구에서는 피부 부착형 표면 전극을 이용하여 갑상선 수술 중 IONM이 안정적으로 활용될 수 있음을 확인하였다. 피부 전극을 이용한 IONM을 준비하는 과정에서 수술의 지 연이 발생하지 않았고, 피부 전극이 피부에서 탈락되는 등의
문제로 인해 위신호소실이 발생한 증례는 없었다. 또한, 신호 소실이 발생한 2예에서 수술 후 성대 마비가 발생하여 이 전 극을 이용한 IONM이 신경 기능을 잘 반영하는 것을 확인할 수 있었다.

Chiang 등이 이 갑상선 수술 중 되돌이후두신경을 감시하 는 방법으로 IONM을 표준화한 이후로 EMG 튜브를 이용한 $\mathrm{IONM}$ 은 갑상선 수술에서 널리 활용되고 있다. 그러나, $\mathrm{EMG}$ 튜브 기반의 IONM은 튜브의 위치 변동 혹은 회전으로 인해 위신호소실이 발생하여 낮은 양성예측도를 보인다는 단점이 있다. 이러한 단점을 극복하기 위해 갑상 연골에 바늘 전극을 삽입하여 근전도 모니터링을 하였으나 이 또한 갑상 연골을 노출하기 위해 피판을 수술 부위보다 더 넓게 들어 올려야 하고, 바늘 전극의 침습성에 따른 합병증의 가능성이 있으며 나이가 많은 환자에서는 갑상 연골의 석회화로 인해 전극 삽 입이 어렵다는 단점이 있다. ${ }^{6}$ 이에 대한 대안으로 덜 침습적인 피부 부착형 전극을 이용한 연구가 보고되고 있다.

$\mathrm{Wu}$ 등근 피부 전극을 부착하여 $\mathrm{EMG}$ 신호를 측정하는 동물실험을 보고했는데, 되돌이후두신경 손상에 대한 정보를 $\mathrm{EMG}$ 튜브 전극과 동일하게 제공할 수 있음을 보여주었다. 또 한 기관의 위치 변화가 있을 때 신호(진폭)가 감소하는 $\mathrm{EMG}$ 튜브와는 달리 피부 부착형 전극은 안정적인 신호를 나타내 어 튜브의 위치 변화에 대한 불안정성도 극복할 수 있음을 보 여주었다. 그러나 EMG 신호의 진폭이 EMG 튜브나 바늘 전 극을 사용한 IONM에 비해 낮은 것을 지적하면서 갑상선 수 술 IONM에 특화된 모양, 크기, 접착력 등을 갖는 전극 개발 의 필요성을 기술하였다. Liddy 등 ${ }^{13)}$ 의 연구에서는 갑상 연 골에 전극을 부착하여 $\mathrm{EMG}$ 신호를 측정하였는데 $\mathrm{EMG}$ 튜 브에 비해 최대 $83 \%$ 정도의 진폭을 보였으나, 잠복기는 차이 가 없었다. 이들은 EMG 튜브와 달리 수술 의사의 시야 내에 전극이 부착되어 있어 직접 통제 가능한 것이 장점이라고 하 였다. 한편, 이 방법은 갑상 연골에 피부 부착형 전극이 부착 되기 어려우므로 봉합사로 고정하는 등의 추가적인 불편함이 있다.

앞선 연구들과 같이 본 연구에서도 피부 부착형 전극을 통 한 IONM은 상대적으로 낮은 진폭을 보였다. Lorenz 등ㄴㄱㅇㅢ 의 연구에서 1996명을 대상으로 미주신경과 되돌이 후두신경의 $\mathrm{EMG}$ 튜브 신호의 진폭과 잠복기를 측정하였다. 왼쪽 미주신 경의 진폭 중앙값이 460(138 1241) $\mu \mathrm{V}$, 오른쪽 미주신경의 진폭 중앙값이 512(168 1593) $\mu \mathrm{V}$ 인 것에 반해, 본 연구에서는 왼쪽 미주신경 진폭 중앙값이 219(101 567) $\mu \mathrm{V}$, 오른쪽 미주 신경의 진폭 중앙값이 231(118 390) $\mu \mathrm{V}$ 으로 측정되었다. 본 기관의 선행 연구에에서도 부착형 전극의 신호가 $\mathrm{EMG}$ 튜브 신호의 $1 / 4$ 정도로 관찰되어 비슷한 결과를 보였다. 이는 연 

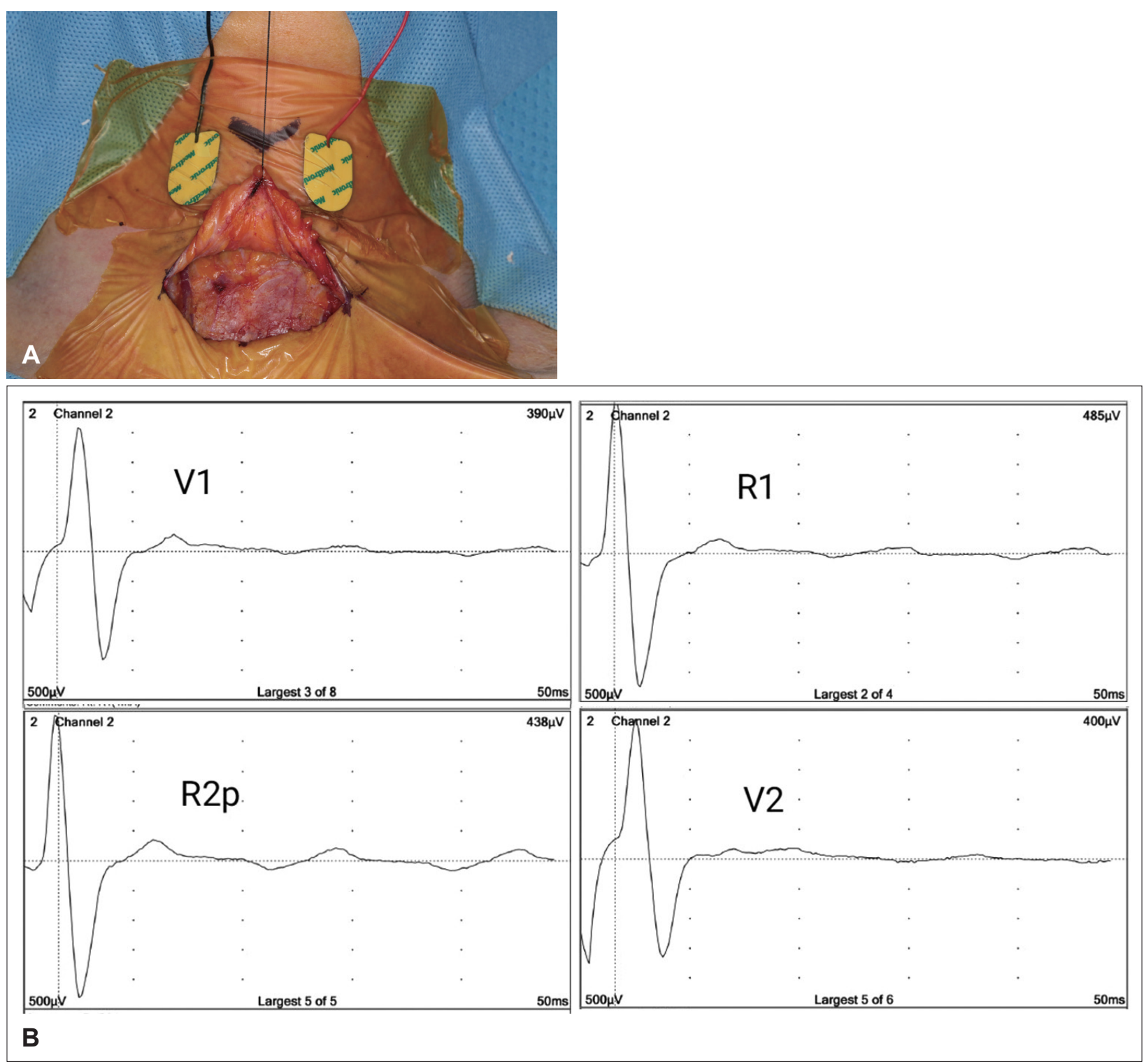

Fig. 1. Attachment of transcutaneous adhesive skin electrodes (A) and acquired electromyogram signals (B).

Table 2. Amplitude of the enrolled nerves at risk at each stage of intraoperative neuromonitoring

\begin{tabular}{lccc}
\hline & Mean \pm SD $(\mu \mathrm{V})$ & Minimum $(\mu \mathrm{V})$ & Maximum $(\mu \mathrm{V})$ \\
\hline V1 & $230.64 \pm 80.01$ & 101 & 567 \\
R1 & $293.48 \pm 123.78$ & 97 & 946 \\
R2p & $317.76 \pm 111.94$ & 98 & 762 \\
R2d & $314.15 \pm 124.77$ & 94 & 986 \\
V2 & $256.04 \pm 87.45$ & 107 & 571
\end{tabular}

SD: standard deviation

구에 적용한 피부 전극이 갑상선 수술 IONM을 위해 개발된 것이 아니며, 성대 근육의 신호가 피부로 전해지는 과정에서 신호 감쇠(signal attenuation)가 발생하기 때문이다. 그러나, 낮은 진폭에도 불구하고 모든 $\mathrm{EMG}$ 신호는 전형적인 이상성 의 모양을 가졌으며 신호 소실은 곧 수술 후 성대 마비로 확
Table 3. Latency of the enrolled nerves at risk at each stage of intraoperative neuromonitoring

\begin{tabular}{lccc}
\hline & Mean \pm SD $(\mathrm{msec})$ & Minimum $(\mathrm{msec})$ & Maximum $(\mathrm{msec})$ \\
\hline R1 & $2.01 \pm 0.64$ & 1.21 & 4.68 \\
R2p & $2.04 \pm 0.66$ & 1.25 & 4.74 \\
R2d & $1.78 \pm 0.66$ & 0.99 & 4.57 \\
V1 Rt & $3.03 \pm 1.01$ & 1.25 & 5.51 \\
V1 Lt & $5.03 \pm 2.38$ & 1.25 & 9.43 \\
V2 Rt & $2.97 \pm 1.02$ & 1.25 & 5.39 \\
V2 Lt & $4.96 \pm 2.35$ & 1.25 & 9.37
\end{tabular}

SD: standard deviation, Rt: right, Lt: left

인되었다. 따라서 지금까지 사용해오던 $\mathrm{EMG}$ 튜브나 바늘 전 극의 한계점을 극복할 대체 방법으로 고려될 수 있겠다. 단, 선행 연구에서 기술된 대로 ${ }^{8)}$ 임상적인 적용을 위해서는 신호 
Table 4. Amplitude $(\mu \mathrm{V})$ of the enrolled nerves at risk according to BMI

\begin{tabular}{llll}
\hline & \multicolumn{1}{c}{ BMI $<24.26(n=50)$} & $B M I \geq 24.26(n=45)$ & $p$ value \\
\hline V1 & $251.57 \pm 89.46(122-567)$ & $213.58 \pm 72.82(101-404)$ & $0.020^{*}$ \\
R1 & $308.65 \pm 134.15(134-946)$ & $276.29 \pm 109.81(97-530)$ & 0.182 \\
R2p & $336.82 \pm 119.78(149-762)$ & $296.16 \pm 99.26(98-550)$ & 0.062 \\
R2d & $334.76 \pm 135.74(161-986)$ & $290.78 \pm 107.81(94-560)$ & 0.070 \\
V2 & $273.39 \pm 95.70(107-571)$ & $236.38 \pm 73.21(127-392)$ & 0.030 \\
\hline
\end{tabular}

*indicates $p<0.05$. BMl: body mass index

소실의 정의(1 2 mA의 자극 시 $100 \mu \mathrm{V}$ 이하의 진폭) 대신 피부 전극 IONM에서의 신호 소실에 대한 정의가 필요할 수 있겠다. 또한 갑상 연골 주변의 피부 피판을 광범위하게 박리 해야 하는 경우 신호 감쇠가 더 크게 나타날 수 있으므로 주 의를 요한다. 이러한 한계에도 불구하고, 부착형 피부 전극은 $\mathrm{EMG}$ 튜브를 사용할 수 없거나 수술 전에 준비가 되지 않은 경우, 또는 비용 문제로 사용하기 어려운 경우 등에 적용할 수 있을 것이다.

본 연구에서는 평균 $\mathrm{BMI}$ 를 기준으로 환자군을 나누어 신 경 신호의 진폭을 비교하였는데, BMI가 높은 군에서 V1과 $\mathrm{V} 2$ 에서 $\mathrm{EMG}$ 진폭이 유의하게 낮았으며 R1-R2p-R2d의 $\mathrm{EMG}$ 신호에서도 통계적 유의성은 없었으나 BMI가 높은 군 에서 진폭이 낮은 경향을 확인할 수 있었다. Nordander 등 ${ }^{15)}$ 도 등세모근의 피부 두께 및 $\mathrm{BMI}$ 와 $\mathrm{EMG}$ 진폭이 반비례 관 계에 있다는 것을 보고하였다. 이는 BMI가 크면 전기 신호의 감쇠가 증가할 수 있음을 시사한다. 따라서, 부착형 피부전 극을 활용한 IONM을 시행할 때는 환자의 $\mathrm{BMI}$ 를 고려하여 $\mathrm{EMG}$ 신호 결과를 분석해야 하겠다. 본 연구는 저자들의 선 행 연구와는 달리 피부 부착형 전극과 $\mathrm{EMG}$ 튜브를 함께 사 용한 것이 아니므로, 두 방법 간의 $\mathrm{EMG}$ 신호 비교는 시행하 지 못했으며 BMI에 따른 EMG 신호의 차이가 EMG 튜브의 경우에도 나타나는지는 확인할 수는 없었다. 또한 피부 부착 형 전극을 이용한 IONM에서의 신호 소실 기준을 정립하기 위해서는 기존의 $\mathrm{EMG}$ 튜브를 함께 사용하는 대단위 임상 연구가 추가될 필요가 있겠다.

결론적으로, 본 연구를 통해 피부 부착형 전극이 갑상선 절 제술 중 IONM의 대안이 될 수 있으며 성대 마비를 예측하 는 데 유용하다는 것을 확인할 수 있었다. 피부 부착형 전극 을 이용한 $\mathrm{EMG}$ 신호는 진폭이 낮다는 한계점이 있으며, 이 는 향후 피부 전극 관련 기술 개발을 통해 해결해야 할 과제 이다.

\section{Acknowledgments}

This study was supported by grants from Hanmi Healthcare. The funding source has no involvement in study design, analysis and interpretation of data.

\section{Author Contribution}

Conceptualization: Hyoung Shin Lee, Sung Won Kim, Kang Dae Lee. Data curation: Sang Gyu Seo, Hyoung Shin Lee, Ki Hun Jo, Sung Won Kim. Formal analysis: Sang Gyu Seo, Hyoung Shin Lee, Sung Won Kim, Kang Dae Lee. Methodology: Hyoung Shin Lee, Sung Won Kim, Kang Dae Lee. Supervision: Hyoung Shin Lee, Sung Won Kim, Kang Dae Lee. Visualization: Ki Hun Jo. Writing - original draft: Sang Gyu Seo, Hyoung Shin Lee. Writing-review \& editing: Hyoung Shin Lee, Kang Dae Lee.

\section{ORCID}

Kang Dae Lee ～https://orcid.org/0000-0003-3143-1180

\section{REFERENCES}

1) Jung KW, Won YJ, Kong HJ, Lee ES. Cancer statistics in Korea: incidence, mortality, survival, and prevalence in 2016. Cancer Res Treat 2019;51(2):417-30.

2) Lee KD, Joo HB, Lee HK, Choi YS, Park YH. Complications following thyroid surgery. Korean J Otolaryngol 2001;44(5):522-7.

3) Zheng S, Xu Z, Wei Y, Zeng M, He J. Effect of intraoperative neuromonitoring on recurrent laryngeal nerve palsy rates after thyroid surgery--a meta-analysis. J Formos Med Assoc 2013; 112(8):463-72.

4) Sun H, Tian W, Jiang K, Chiang F, Wang P, Huang T, et al. Clinical guidelines on intraoperative neuromonitoring during thyroid and parathyroid surgery. Ann Transl Med 2015;3(15):213.

5) Yang S, Zhou L, Lu Z, Ma B, Ji Q, Wang Y. Systematic review with meta-analysis of intraoperative neuromonitoring during thyroidectomy. Int J Surg 2017;39:104-13.

6) Chiang FY, Lu IC, Chang PY, Dionigi G, Randolph GW, Sun H, et al. Comparison of EMG signals recorded by surface electrodes on endotracheal tube and thyroid cartilage during monitored thyroidectomy. Kaohsiung J Med Sci 2017;33(10):503-9.

7) Wu CW, Chiang FY, Randolph GW, Dionigi G, Kim HY, Lin YC, et al. Transcutaneous recording during intraoperative neuromonitoring in thyroid surgery. Thyroid 2018;28(11):1500-7.

8) Lee HS, Oh J, Kim SW, Jeong YW, Wu CW, Chiang FY, et al. Intraoperative neuromonitoring of recurrent laryngeal nerve during thyroidectomy with adhesive skin electrodes. World J Surg 2020; 44(1):148-54.

9) Kim HY, Sun H, Chai YJ, Tufano R, Dralle H, Navarra G, et al. Loss of the neuromonitoring signal on the first side in planned total thyroidectomy. J Endocr Surg 2017;17(3):89-95.

10) Chiang FY, Lee KW, Chen HC, Chen HY, Lu IC, Kuo WR, et al. Standardization of intraoperative neuromonitoring of recurrent laryngeal nerve in thyroid operation. World J Surg 2010;34(2):223-9.

11) Wu CW, Hao M, Tian M, Dionigi G, Tufano RP, Kim HY, et al. Recurrent laryngeal nerve injury with incomplete loss of electromyography signal during monitored thyroidectomyevaluation and outcome. Langenbecks Arch Surg 2017;402(4):691-9.

12) Chen HC, Pei YC, Fang TJ. Risk factors for thyroid surgery-related 
unilateral vocal fold paralysis. Laryngoscope 2019;129(1):275-83.

13) Liddy W, Lawson BR, Barber SR, Kamani D, Shama M, Soylu S, et al. Anterior laryngeal electrodes for recurrent laryngeal nerve monitoring during thyroid and parathyroid surgery: New expanded options for neural monitoring. Laryngoscope 2018;128(12):2910-5.

14) Lorenz K, Sekulla C, Schelle J, Schmeiss B, Brauckhoff M, Dralle $\mathrm{H}$, et al. What are normal quantitative parameters of intraoperative neuromonitoring (IONM) in thyroid surgery? Langenbecks Arch Surg 2010;395(7):901-9.

15) Nordander C, Willner J, Hansson GA, Larsson B, Unge J, Granquist $\mathrm{L}$, et al. Influence of the subcutaneous fat layer, as measured by ultrasound, skinfold calipers and BMI, on the EMG amplitude. Eur J Appl Physiol 2003;89(6):514-9. 